REVISTA DE DERECHO UNED, NÚM. 24, 2019

\title{
EL BIODERECHO ANTE EL RETO DE LA GESTACIÓN SUBROGADA
}

\author{
THE BIOLAW FACING THE CHALLENGE \\ OF GESTATIONAL SURROGACY
}

\author{
JACINTO J. MARABEL
}

Doctor en Derecho. Comisión Jurídica de Extremadura

Resumen: El Bioderecho es una disciplina que ha venido desarrollándose en las últimas décadas a remolque de los avances tecnológicos en materia médica. La normativa, aprobada en base a la jurisprudencia generada por la casuística, ha llegado a reconocer derechos de tercera generación, como la autonomía del paciente o la objeción de conciencia del médico, impensables hasta hace bien poco tiempo. Por esta razón, en la actualidad uno de los retos del legislador en esta materia está el saber conjugar los derechos derivados de las prácticas de gestación subrogada, entre los que se encuentran los de la mujer en general, así como los de la gestante y los hijos nacidos de las mismas, en los que la jurisprudencia comienza a abrir una vía de reconocimiento.

Palabras clave: Bioderecho; Gestación subrogada; seguridad jurídica; derechos de la mujer; derechos del niño.

Abstract: The Biolaw is a discipline that has been developed in the last decades to trailer of the technological advances in medical matter. The regulation, approved on the basis of the jurisprudence generated by the casuistry, has come to recognize third generation rights, such as the autonomy of the patient or the medical conscientious objection, unthinkable until very recently. For this reason, at present one of the challenges of the legislator in this matter is to know how to conjugate the rights derived from the practices of su- 
rrogacy, among which are those of the woman in general, as well as those of the pregnant woman and the children born of the same, in which the jurisprudence begins to open a way of recognition.

Keywords: Biolaw; gestational surrogacy; Legal certainty; women's rights; children's rights.

Recepción original: 08/11/2018

Aceptación original: 23/01/2019

Sumario: I. Breve síntesis del paradigma Bioético. II. El progreso científico como génesis de la configuración del Bioderecho. III. El vacío legal de las prácticas de gestación subrogada en España. IV. Bibliografía.

\section{BREVE SÍNTESIS DEL PARADIGMA BIOÉTICO}

Una vez finalizada la II Guerra Mundial, las democracias occidentales plantearon la necesidad de comprometer sus ordenamientos jurídicos con la mayor parte de los principios y valores consensuados y generalizados por la comunidad política internacional, obligándose a su cumplimiento, con la finalidad de promover las relaciones pacíficas entre los Estados y evitar, en la medida de lo posible, la escala de hostilidades que había conducido al mayor enfrentamiento de la Historia de la Humanidad. Estos derechos de tercera generación, recogidos en un primer momento con carácter dispositivo en distintos instrumentos internacionales, fueron adquiriendo carácter vinculante a través de los sucesivos acuerdos, convenios y tratados firmados por los Estados, poniéndose de manifiesto muy pronto la dificultad que, a efectos prácticos, suponía trasladarlos a las normativas nacionales cuando las convicciones religiosas y los valores éticos sobre los que se asentaban eran vertiginosamente superados por los avances científicos y tecnológicos contemporáneos.

El proceso se aceleró notablemente en el último cuarto del siglo xx y la comunidad internacional comenzó a clamar por un modelo de paradigma que acabara por dar sentido a las novísimas relaciones surgidas entre el Hombre y la Ciencia. Una primera reflexión fue articulada a partir de la moral religiosa de los países católicos, en tanto conformaban la punta de lanza mayoritaria del progreso tecnológico en aquellos momentos. Fue así como los postulados procedentes de la Universidad de Georgetown acabaron siendo el basamento sobre el que en los años setenta se iría construyendo una nueva disciplina que recibió el nombre de Bioética, un término res- 
catado del concepto general enunciado por el teólogo Fritz Jahr en 1927 para describir las relaciones entre el ser humano y el resto de seres vivos ${ }^{1}$. En base a ello, en 1978 el teólogo Warren Reich acuñó la primera acepción de la Bioética, entendida como «el estudio sistemático de la conducta humana en el área de las ciencias de la salud, cuando tal conducta viene examinada a la luz de los valores y de los principios morales $»^{2}$.

La Bioética nace por tanto como ciencia que trata de dar respuesta crítica a un modo de entender el desarrollo científico y sus consecuencias, tanto para el ser humano como para la sociedad en su conjunto. Por esta razón, sus soluciones, puntos de vista y metodologías resultan transversales y superan con frecuencia los criterios estrictamente médico-científicos para llegar a abarcar ámbitos propios de otras disciplinas, tales como la Antropología, la Economía o el Derecho. Este último campo ha mantenido siempre un diálogo completo con la Bioética, en una conversación bidireccional que no puede darse nunca por cerrada so pretexto de quedar obsoleto frente a una sociedad que cabalga a lomos de una tecnología desbocada. Y como quiera que uno de los principales retos del Derecho está en otorgar soluciones a las múltiples demandas que originan los planteamientos éticos en las sociedades avanzadas, en los últimos tiempos ha destacado una parte muy importante del mismo a la rama vinculada a la ética derivada del ejercicio de la medicina: el Bioderecho ${ }^{3}$.

Esta disciplina ha ido conformándose a lo largo de todo este tiempo a remolque de las resoluciones judiciales que, en similares términos, atienden al nombre de Biojurisprudencia ${ }^{4}$. A su vez, los razonamientos expuestos por los tribunales a los que por primera vez se enfrentaban estos dilemas morales, casi exclusivamente procedentes del ámbito anglosajón, no eran sino influencia de los postulados bioéticos. Así fueron articulados los fundamentos legales que en la actualidad ordenan el derecho a la autonomía del paciente y el

${ }^{1}$ Vid. JAHR, Fritz. "Bioethics. A panorama of the human being's ethical relations with animals and plants». Kosmos, Gesellschaft der Naturfreunde, Stuttgart, 1927.

${ }^{2}$ REICH, Warren T. Encyclopedia of Bioethics. Vol. I. MacMillan Free Press. Nueva York. 1978; pág. 19.

3 Vid. PUIGPELAT MARTÍ, Francesca. «Bioética y Derecho», en ATIENZA RODRÍGUEZ, M. (coord.) Teoría del Derecho y Filosofía del Derecho. Base de datos de bibliografía jurídica. Iustel. Madrid, 2003.

4 APARISIS MIRALLES, Ángela. "Bioética, Bioderecho y Biojurídica (Reflexiones desde la filosofía del derecho)». Anuario de Filosofía del Derecho, n. ${ }^{\circ} 24$. Sociedad Española de Filosofía Jurídica y Política. Ministerio de Justicia, 2007; pp. 63-84. 
derecho a la objeción de conciencia del médico, entre otros. Y así, casi con certeza porque en esta materia no hay verdades absolutas, se puede asegurar que ocurrirá con aquellas otras situaciones similares en las que, hoy por hoy, la opinión pública demanda seguridad jurídica y aún no han sido afrontadas con resolución, tales como aquellos dilemas circunscritos a la investigación y tratamiento con embriones humanos, o los efectos legales derivados de la gestación subrogada, de la que a continuación pasaremos a ocuparnos.

\section{EL PROGRESO CIENTÍFICO COMO GÉNESIS DE LA CONFIGURACIÓN DEL BIODERECHO}

Los principios generales de la Bioética obedecen a una génesis compleja, sobre la que no procede extenderse en el presente trabajo, en tanto nos obligaría a alejarnos de nuestro propósito y remontarnos, por ejemplo, a las teorías propuestas hace más de un siglo por Georg Weiss sobre el fundamento de la escuela hipocrática en los actuales códigos médicos deontológicos. Por tanto, deberá bastarnos con apuntar que los grandes descubrimientos médicos del siglo XIX dejaron abiertas multitud de puertas por las que se coloraron los grandes dilemas éticos de nuestro tiempo, como fue el enunciado de la teoría celular de Rudolf Virchow, los descubrimientos de los bacilos de ántrax, tuberculosis y cólera de Robert Koch, o el aislamiento de la cepa de penicilina por Louis Pasteur, entre otros eminentes logros de la época. Y es que, desde las prácticas eugenésicas, justificadas en base al darwinismo social de Francis Galton, los conflictos bioéticos han traído su causa en axiomas científicos. Precisamente, las teorías de Hebert Spencer justificarían las segregaciones raciales nazis y las esterilizaciones masivas de sectores sensibles de población, así como otros abominables experimentos llevados a cabo por Joseph Mengele y su equipo médico. Las causas que enjuiciaron a este y otros criminales nazis propiciaron la declaración de principios que en la actualidad limitan la investigación médica, fueron recogidos en los llamados Códigos de Nuremberg 5 .

Sobre este decálogo de principios dispositivos destacaban especialmente la prestación del consentimiento del paciente, el carácter finalista, público y universal de la experimentación médica, así como la aplicación de medidas proporcionales en la clínica asistencial, que tuvieron un protagonismo destacado en la II Asamblea Mé-

${ }^{5}$ Vid. Trials of War Criminals before the Nuerberg Military Tribunals under control Council Law n. ${ }^{\circ}$ 10. Vol. II. The Medical Case. Nuerberg, 1949. 
dica Mundial reunida en Ginebra en septiembre de 1948, aún bajo la influencia de los Juicios de Nuremberg. Aquellas jornadas concluyeron con la Declaración de Ginebra ${ }^{6}$, un texto de indudable índole programática en el que se armonizaban los principios hipocráticos clásicos con un incipiente código deontológico de pretensiones universales, dirigido a la profesión médica. Y sin duda, dicho texto tuvo una influencia fundamental cuando apenas meses más tarde, el 10 de diciembre de 1948, la Asamblea General de las Naciones Unidas, aprobó la Declaración Universal de los Derechos Humanos ${ }^{7}$ garantizando el derecho a la salud y la dignidad de la persona, así como la interdicción de los tratos crueles o degradantes.

Con frecuencia, la importancia otorgada a estos principios universales han obviado el carácter fundacional de la Declaración de Ginebra en la articulación de los postulados que fundamentan la Bioética, pero lo cierto es que sus fundamentos, acrisolados al Código de Nuremberg, conformaron en su mayor parte la Declaración de Helsinki que durante años sería comúnmente aceptada como la guía deontológica de referencia entre la profesión médica ${ }^{8}$. En efecto, la XVIII Asamblea Médica Mundial reunida para la ocasión en la capital de Finlandia en junio de 1964, asumió ambos textos y diferenció dos tipos de investigaciones: la diagnóstica o terapéutica, realizada en beneficio del paciente; y la científica propiamente dicha, sin finalidad terapéutica práctica a corto plazo.

La diferencia es importante, porque en el primer caso estaría justificada la investigación sin el consentimiento del paciente, legitimando la actuación en su propio beneficio y justificando que, en última instancia, se mantuvieran una serie de prácticas éticamente reprobables desde el punto de vista actual. Y ello porque el razonamiento suponía reconocer la primacía del utilitarismo o consecuen-

${ }^{6}$ Los principios que informan la Declaración de Ginebra, adoptada por la II Asamblea General de la Asociación Médica Mundial en septiembre 1948, ha sido enmendados y revisados en numerosas ocasiones, por lo que su redacción actual puede consultada en la sede electrónica de la propia Asociación Médica Mundial. Vid. Https://www.wma.net/es/policies-post/declaracion-de-ginebra/ [Consultada el 7 de noviembre de 2018].

${ }^{7}$ Vid. http://www.un.org/es/universal-declaration-human-rights/ [Consultada el 7 de noviembre de 2018].

${ }^{8}$ Al igual que la anterior, los principios que informan la Declaración de Helsinki, adoptada por la XVIII Asamblea General de la Asociación Médica Mundial en junio de 1964, ha sido enmendados y revisados en numerosas ocasiones, por lo que su redacción actual puede consultada en la sede electrónica de la propia Asociación Médica Mundial. Vid. https://www.wma.net/es/policies-post/declaracion-de-helsinkide-la-amm-principios-eticos-para-las-investigaciones-medicas-en-seres-humanos [Consultada el 7 de noviembre de 2018]. 
cialismo anglosajón sobre el principio de la voluntad del paciente, que ya por entonces comenzaba a despuntar. Así, este tipo de acciones médicas estarían justificadas siempre que se obtuviera un resultado ventajoso para el máximo número de enfermos, primando el beneficio universal por encima de la ética individual.

Paradójicamente, al mismo tiempo que la práctica médica revelaba un utilitarismo sin complejos, el Derecho Internacional buscaba fórmulas que dotaran de fuerza vinculante los principios programáticos enunciados en la Declaración Universal de los Derechos Humanos. De este modo la Asamblea General de la ONU, adoptó mediante Resolución de 16 de diciembre de 1966, dos instrumentos vinculantes que vendrían a completar los efectos jurídicos de la anterior: el Pacto Internacional de Derechos Civiles y Políticos y el Pacto Internacional de Derechos Económicos, Sociales y Culturales ${ }^{9}$. Ambos forman, junto a la propia Declaración Universal de los Derechos Humanos y sus protocolos de desarrollo, la Carta Internacional de los Derechos Humanos, de obligado cumplimiento entre los Estados firmantes. El artículo 12 del segundo consagra la protección a la salud en términos generales, mientras que el artículo 7 del primero prohibió la experimentación médica sin el consentimiento del paciente.

Sin embargo, ambos instrumentos, conocidos también como Pactos de Nueva York, entraron en vigor diez años más tarde, por lo que en la práctica clínica continuó imperando el utilitarismo. Y la filosofía que subyacía en sus fundamentos dotaba de carácter legitimador a algunos experimentos que hasta entonces se venían realizando con pacientes sin su consentimiento, que no habían trascendido aún a la opinión pública pese a ser generalmente conocidos por la comunidad médica internacional. Hasta que en el contexto de la crisis política originada por el Watergate estalló el caso Tuskegee, y el clamor social instó a remover los paradigmas éticos asistenciales. El detonante fue un funcionario del Departamento de Salud Pública que filtró al periodista Jean Heller ciertos documentos donde se revelaban una serie de experimentos, realizados durante cuarenta años con el conocimiento de distintos Ejecutivos norteamericanos. En base a esta información, el 26 de julio de 1972, The New York Times publicó un artículo acusando al Gobierno de financiar una serie de estudios en Macon, un condado fundamentalmente agrícola de Alabama, con la finalidad de comprobar la evolución de afectaciones

9 Vid. https://undocs.org/es/A/RES/2200(XXI). [Consultada el 7 de noviembre de 2018]. 
cardiovasculares en enfermos de sífilis, todos ellos sujetos de población negra y aparceros de bajo estrato social.

Por aquel entonces, la toxicidad de los tratamientos emprendidos se justificó en aras del beneficio general y el progreso de la ciencia médica $\mathrm{y}$, aunque llevaron a la muerte a muchos de los pacientes, en 1934 el proyecto logró descubrir los efectos de la penicilina en la erradicación de la enfermedad. Los resultados fueron contemplados en la Ley Henderson aprobada diez años más tarde por el Congreso, mediante la cual se instauraba el tratamiento farmacológico universal en enfermos de sífilis. Pero los impulsores del Experimento Tuskegee $^{10}$, obviando los imperativos legales, en lugar de penicilina continuaron aplicando placebo a sus pacientes.

En su artículo, Jean Heller mencionaba que ciento cincuenta y cuatro pacientes habían muerto por enfermedades cardiovasculares relacionadas con la enfermedad. Y, aunque si bien es cierto que los informes posteriores rebajaron esta cifra a ciento veintiocho, no lo es menos que también pusieron al descubierto la nada desdeñable cifra de cuarenta mujeres, esposas de los pacientes, infectadas por la enfermedad, así como diecinueve niños nacidos de estas relaciones y diagnosticados de sífilis congénita. Los datos fueron hechos públicos por la Comisión Nacional para el Estudio de las Cuestiones Éticas Relacionadas con la Investigación Médica en Sujetos Humanos, instada por el senador Edward Kennedy y creada a partir de la Ley Nacional de Investigación, de 12 de julio de $1974^{11}$, que en los años sucesivos iría publicando así mismo una serie de trabajos relacionados con cuestiones éticas directamente imbricadas en el ámbito asistencial, como la consideración e integridad del feto, los derechos de los menores o la dignidad de los incapacitados, entre otras.

La propuesta del senador Kennedy tenía un inmediato antecedente en el ámbito familiar, puesto que tres años antes habían financiado a la Universidad de Georgetown para que creara el primer centro de estudios para la Reproducción Humana y Bioética, poniendo al frente del mismo al eminente ginecólogo Andre Hellegers. La denominación del centro, más tarde conocido como Instituto Kennedy de Bioética ${ }^{12}$, obedecía a los postulados enunciados por el oncólogo

${ }^{10}$ MARABEL MATOS, Jacinto J. El Derecho Fundamental de Libertad Religiosa en el ámbito de los servicios públicos sanitarios. Dykinson. Madrid, 2017; pág. 54.

${ }_{11}$ Vid. https://history.nih.gov/research/downloads/PL93-348.pdf. [Consultada el 7 de noviembre de 2018].

12 Puede consultarse su historia y tener acceso a información relacionada con el mismo en la web oficiald de la institución. Vid. https://kennedyinstitute.georgetown. edu . [Consultada el 7 de noviembre de 2018]. 
Van Rensselaer Potter, que se había encargado de acotar la disciplina en una obra considerada pionera en la materia y que tituló Bioética: un puente hacia el futuro. En la misma, Potter abogaba por una nueva deontología que integrara la filosofía hipocrática, entendida como el conjunto de directrices que debían marcan el ejercicio profesional, con un nuevo paradigma que amparase el hasta entonces impreciso significado de las ciencias biológicas ${ }^{13}$.

Las propuestas de Potter tuvieron un inmediato predicamento en la comunidad científica internacional, culminando con una serie de principios enunciados por George H. Kieffer a finales de esa misma década ${ }^{14}$. Con las salvaguardas precisas, pues no olvidemos que ya por entonces estaban plenamente en vigor los Pactos de Nueva York, sus fundamentos acabarían por influir de modo decisivo en los protocolos que regulan las actuaciones médicas en el campo de la eutanasia, de la genética y de las tecnologías reproductivas, delimitando el ámbito entre la ética pública y la ciencia médica. Y aún antes sentaron las bases que concluyeron con los resultados de las investigaciones del Experimento Tuskegee, llevadas a cabo por la Comisión Nacional para el Estudio de las Cuestiones Éticas.

El trabajo, que se hizo público el 30 de septiembre de 1979, recibió el nombre de Informe Belmont: Principios Éticos y Pautas para la Protección de los Pacientes ${ }^{15}$, e incluyó en sus resultados, además de los trabajos llevados a cabo en el seno de las investigaciones sobre el caso Tuskegee, otros experimentos similares. Principalmente las prácticas clínicas llevadas a cabo por las mismas fechas en el Willowbrook State School, donde más de setecientos menores discapacitados fueron inoculados del virus de la hepatitis C, y las del Jewish Disease Hospital de Nueva York, donde se hizo lo propio con grupos de ancianos ingresados, a fin de conocer la evolución de los tumores cerebrales $^{16}$. El Informe Belmont resulta especialmente importante porque sentó los postulados básicos de los parámetros éticos que de-

13 Vid. POTTER, Van Rensselaer. Bioethics: Bridge to the future. Englewood Cliffs. New Jersey. 1971. No obstante, sus fundamentos habían sido expuestos en un artículo anterior. POTTER, V. R. «Bioethics, the Science of Survival». Perspectives in Biology and Medicine. Vol. XIV, $\mathrm{n} .{ }^{\circ}$ 1. University of Kansas Medical Center. 1970: págs. 127-153.

${ }^{14}$ Vid. KIEFFER, George H. Bioethics: A Textbook of Issue. Reading AddisonWesley. Londres, 1979.

15 Puede consultarse toda la información relativa al Informe Belmont y a la Comisión Nacional para el Estudio de las Cuestiones Éticas en la web de la Oficina para la Protección de la Investigación Humana del propio Departamento de Salud del Gobierno de los Estados Unidos. Vid. https://www.hhs.gov/ohrp/regulations-andpolicy/belmont-report/index.html. [Consultada el 7 de noviembre de 2018].

16 MARABEL MATOS, J. J. El Derecho Fundamental..., Op. cit; pág. 54. 
bían presidir la práctica médica, fundamentados en el respeto a los pacientes, la justicia y la beneficencia. Aunque hay que decir que casi al mismo tiempo, Tom Beauchamp, un filósofo utilitarista que había formado parte de la propia Comisión, y James Childress, un reconocido experto en deontología médica, añadieron un cuarto pilar: el principio de no maleficencia ${ }^{17}$.

Teniendo en cuenta estos antecedentes, podría afirmarse que la preocupación central de la Bioética consiste en armonizar los desarrollos biomédicos con la dignidad de cada ser humano, garantizando la dignidad del paciente, aunque sin mantenerse ajena a la circunstancias particulares de cada caso. Tal vez por ello algunos autores han tratado de establecer jerarquías entre los cuatro pilares tradicionalmente asumidos por la Bioética, razonando sobre la oportunidad de conjugarlos con otros criterios, tales como el de Honestidad o el de Eficiencia ${ }^{18}$, o bien buscar algún otro mediador y prevalente entre todos ellos, como la acepción general enunciada por John Rawls para el Principio de Justicia ${ }^{19}$.

Las teorías bioéticas llegaron a España a través del Instituto Borja de Bioética, adscrito a la Facultad de Teología de la Universidad Ramón Llull de Barcelona, dirigido por entonces por el jesuita Francesc Abel i Fabre, aunque en 1988 la rama secular consiguió abrirse paso a través del master de bioética impulsado por el doctor Diego Gracia Guillén en la Universidad Complutense de Madrid, germen del grupo de estudios que con posterioridad daría lugar al Instituto de Bioética de la Fundación de Ciencias de la Salud. Para este último sector de la doctrina, los cuatro pilares de la Bioética se corresponden con esbozos morales, y al contrario de lo que sucede en el sistema de referencia ontológico donde existen principios universalmente válidos, es cambiante. Esto quiere decir que el conjunto de valores bioéticos evoluciona a la par que las investigaciones médico científicas van produciendo sus resultados, aunque siempre es posi-

17 Vid. BEAUCHAMP, Tom L., CHILDRESS, James Franklin. Principles of Biomedical Ethics. Oxford University Press. Nueva York, 1979.

18 Sin ánimo de ahondar en la cuestión, cuyo estudio excede al presente trabajo, el profesor Martín Sánchez ha advertido sobre esta controversia, en la que algunos autores, partiendo de una ética de mínimos, se inclina a favor de la primacía del Principio de Autonomía, mientras que otra corriente aboga por el Principio de Justicia criterio mediador entre la Autonomía y la Beneficencia, añadiendo los a su juicio necesarios Principios de Honestidad y Eficiencia que deben presidir todo tipo de relaciones bioéticas. MARTÍN SANCHEZ, Isidoro (Coord.). Bioética, Religión y Salud. Consejería de Sanidad y Consumo de la Comunidad de Madrid. Madrid, 2005; pp. 17-20.

${ }_{19}$ Vid. RAWLS, John. A Theory of Justice. Oxford University Press. Nueva York, 1999.

(C) UNED. Revista de Derecho UNED, núm. 24, 2019 
ble exigir una ética de mínimos, que se correspondería con los principios de No Maleficencia y Justicia, en tanto sistema garantista del derecho a no discriminación ${ }^{20}$.

En cualquier caso, el objeto del presente trabajo no es entrar a debatir sobre la jerarquización o primacía de unos u otros principios, por lo que debemos retomar el relato señalando que, con anterioridad a las conclusiones de la Comisión Nacional para el Estudio de las Cuestiones Éticas en este ámbito, las diferencias asumidas en la Declaración de Helsinki en cuanto a la investigación diagnóstica y científica, habían sido reducidas y asimiladas en beneficio del enfermo en el curso de la XXIX Asamblea Médica Mundial, celebrada en Tokio en octubre de $1975^{21}$. La comunidad médica había abandonado con anterioridad al Informe Belmont los postulados utilitaristas que hasta entonces habían presidido la deontología profesional, por lo que el camino para la emancipación del derecho a la autonomía de la voluntad del paciente, como directriz principal a tener en cuenta en aquellos casos de conflictividad bioética, había sido desbrozado finalmente.

De este modo, en 1977 y ya en el marco comunitario, se creó un Grupo Europeo de Ética de la Ciencia y de las Nuevas Tecnologías cuya finalidad era asesorar a la Comisión en los aspectos éticos relacionados con la materia, así como elaborar propuestas para la puesta en valor de una normativa comunitaria que, en la práctica y todo hay que decirlo, resulta cada día más inabarcable. En cualquier caso, siguiendo sus dictámenes el Consejo Europeo acabó aprobando, entre otras, la Directivas 219/1990 de 23 de abril, relativa a la utilización confinada de microorganismos modificados genéticamente, 597/1991, de 3 de mayo, sobre ensayos clínicos, y 44/1997, de 6 de junio, sobre la protección jurídica de las invenciones biotecnológicas.

A su vez, el Parlamento Europeo también fue dando publicidad a los estudios de ciertas comisiones que, en última instancia, acabaría por sentar la base de los actuales instrumentos normativos que regulan las relaciones bióeticas. De este modo, cabe destacar las resolu-

${ }^{20}$ Vid. GRACIA GUILLÉN, Diego. Procedimientos de decisión en ética clínica. Eudema. Madrid, 1991.

${ }^{21}$ La Declaración de Tokio, adoptada en el seno de la XXIX Asamblea Médica Mundial de octubre de 1975, ha sido revisada tres veces, por lo que su redacción actual puede ser consultada en la en la sede electrónica de la propia Asociación Médica Mundial. Vid. https://www.wma.net/es/policies-post/declaracion-de-tokiode-la-amm-normas-directivas-para-medicos-con-respecto-a-la-tortura-y-otros-tratoso-castigos-crueles-inhumanos-o-degradantes-impuestos-sobre-personas-detenidaso-encarceladas. [Consultada el 7 de noviembre de 2018]. 
ciones de 16 de marzo de 1989, sobre los problemas éticos y jurídicos que planteaba la manipulación genética, y de igual fecha sobre la fecundación artificial in vivo e in vitro, así como la Resolución del Parlamento Europeo, de 28 de octubre de 1993, referida a la clonación del embrión humano.

Y poco más tarde, el 20 de septiembre de 1996, daría a conocer la Resolución relativa a la Protección de los Derechos Humanos y de la Dignidad Humana en el marco de la aplicación de la Biología y de la Medicina, cuyas conclusiones suponen el antecedente inmediato del vigente Convenio de Oviedo, nombre por el que usualmente se conoce el Convenio para la protección de los Derechos Humanos y la Dignidad del Ser Humano con respecto a las aplicaciones de la Biología y la Medicina, firmado en el seno del Consejo de Europa el 4 de abril de 1997. Con carácter vinculante para los estados signatarios, representa el marco legal principal que, en el orden internacional, vincula y garantiza los postulados bioéticos con la defensa y promoción de los derechos humanos. El Convenio fue formalizado en la ciudad de Oviedo y ratificado por España el 23 de julio de 1999, entrando en vigor con plenos efectos el 1 de enero de $2000^{22}$.

Existen diversos instrumentos internacionales que deben ser tenidos en cuenta a la hora de interpretar el clausulado del Convenio de Oviedo, como la Declaración sobre el Genoma Humano y los Derechos Humanos, de 11 de noviembre de 1997 y la Declaración sobre los Datos Genéticos Humanos, de 16 de octubre de 2003, aprobadas por la UNESCO ${ }^{23}$. Ambas son antecedentes inmediatos de la Declaración Universal sobre Bioética y Derechos Humanos, aprobada por el mismo organismo el 19 de octubre de $2005^{24}$, en la que se consagra definitivamente el derecho a la autonomía de la persona en lo que se refiere a la facultad de adoptar decisiones. Pero en cualquier caso y con anterioridad a todos ellos, hay que señalar que la ratificación del Convenio de Oviedo supuso la adaptación del ordenamiento jurídico nacional a un clausulado que obligaba en cuestiones éticas, por lo que la importancia del mismo resulta esencial para explicar la consagración de los derechos de los pacientes en nuestro país, instando toda una serie de preceptos con carácter vinculante que por primera vez tienen en cuenta los principios éticos y la dimensión so-

${ }^{22}$ Vid. Boletín Oficial del Estado (BOE), de 20 de octubre de 1999.

${ }_{23}$ Vid.http://portal.unesco.org/es/ev.phpURL_ID $=13177 \&$ URL_DO=DO_ TOPIC\&URL_SECTION=201.html. http://portal.unesco.org/es/ev.php-URL_

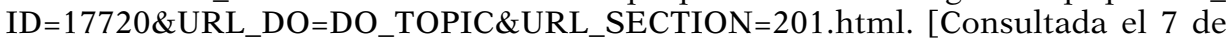
noviembre de 2018].

${ }_{24}$ Vid. http://portal.unesco.org/es/ev.php-URL_ID=31058\&URL_DO=DO_ TOPIC\&URL_SECTION=201.html. [Consultada el 7 de noviembre de 2018].

(C) UNED. Revista de Derecho UNED, núm. 24, 2019 
cial de los pacientes en el marco internacional. Y lo hace tomando como base los precedentes de la tradición jurisprudencial norteamericana, fundamentalmente los célebres Casos Schloendorff contra The Society of New York Hospital, de 19 de enero de 1914, y Salgo contra Leland Standford, Jr. University Board Of Trustees, de 22 de octubre de $1952^{25}$.

Estos y otros pronunciamientos judiciales fueron clave en el desarrollo de los derechos del paciente, porque la jurisprudencia, tanto la foránea o como la ordinaria o la constitucional, resultan la antesala del reconocimiento y plasmación legal de los mismos. Así, algunos autores han llegado a afirmar que, si bien a los estudiosos del Derecho les corresponde abordar una reflexión teórica más allá de la mera perspectiva clásica de la filosofía jurídica, sin duda son los tribunales los que están llamados a desarrollar una amplia reflexión o crítica del marco de los principios fundamentales en el que se insertan los postulados bioéticos.

Podría hablarse por tanto de una Biojurisprudencia, a través de la cual sería lícito exigir del juzgador una extensión de sus razonamientos más allá del fondo del asunto. Más allá y según la catedrática de Bioética de la Universidad de Istmo (Guatemala) Ángela Aparisi, «de la mera descripción fáctica de cómo es la legislación vigente en estas cuestiones... Correspondiéndole —al igual que la filosofía del derecho-, reflexionar sobre las normas vigentes, a la luz del principio de la dignidad humana y de los derechos humanos» ${ }^{26}$.

Conforme con esto, resulta indudable que la Biojurisprudencia auxilia y fundamenta la Biolegislación, entendida como el marco jurídico que sostiene el campo de actuación de las relaciones bioéticas. Este último neologismo integraría todas aquellas normas específicas, promulgadas para regular los nuevos problemas derivados de los avances médicos, como los trasplantes de órganos, las técnicas de fecundación asistida o la propia terapia genética, pero también las que, con carácter particular, acaban reconociendo derechos con ascendencia de índole general como la autonomía del paciente o la objeción de conciencia del médico. Cuestión más controvertida sería aceptar el mismo concepto, tal y como defiende un sector de la doctrina, para definir aquellos instrumentos internacionales que, como los citados convenios y cartas de derechos fundamentales, con

25 Vid. https://biotech.law.lsu.edu/cases/consent/schoendorff.htm. https://caselaw.findlaw.com/ca-court-of-appeal/1759823.html. [Consultada el 7 de noviembre de 2018].

26 APARISI MIRALLES, A. «Bioética, Bioderecho y Biojurídica»..., Op. cit.; págs. 63-84. 
carácter general forman la cúspide de un hipotético sistema kelseniano de protección los de pacientes ${ }^{27}$.

En todo caso podría teorizarse con un Bioderecho como respuesta al fenómeno social, verdadero hito en la Historia de la Humanidad, que supone la revolución científica y el progreso tecnológico que continúa en marcha. La investigación constante, la búsqueda progresiva de innovación y la actualización de conocimientos, entre otros singulares caracteres de la ciencia médica, dificultan la delimitación de su estudio desde los postulados tradicionales, por lo que el Bioderecho se erige como una disciplina eficaz y ágil que resuelva los interrogantes que se plantean desde la ética y la medicina, estableciendo ese común denominador entre ambas disciplinas que coadyuve a converger en la búsqueda de soluciones, si no unívocas al menos pacíficas.

Ello vendría a justificar en última instancia la urgencia por otorgar un marco legal general, una Biolegislación, en la que se trate de ordenar o fijar los derechos de todos los implicados en las relaciones médicos asistenciales, por cuanto la casuística se habría desenvuelto hasta ahora y en gran parte desde la óptica del derecho judicial; es decir: desde la mencionada Biojurisprudencia. En definitiva y como señaló en su momento el recordado profesor Gregorio Peces-Barba, la necesidad de una teoría general del Bioderecho estaría justificada en aras de la seguridad jurídica del sistema, pues hasta ahora la Biolegislación resulta siempre superada por la práctica diaria y la Biojurisprudencia, fundamentalmente la ordinaria y dada su inmediatez, no llega a alcanzar una visión integral del problema ${ }^{28}$.

Las soluciones aportadas por la Biojurisprudencia en interpretación de aquella, deben servir para abordar con garantías el gran número de supuestos de este tipo con el que diariamente nos encontramos en nuestros hospitales. De hecho, las distintas resoluciones judiciales y especialmente la doctrina emanada del Tribunal Constitucional, precedieron toda una suerte de Biolegislación en la que finalmente la mayor parte de este tipo de pretensiones quedaran garantizadas. Sin embargo, el avance imparable de la técnica alcanzando logros impensables para la ciencia médica hasta hace bien poco, continúa suscitando novísimas cuestiones éticas o morales que habrá que dilucidar a corto plazo, tales como las pretensiones de reconocimiento de los llamados derechos reproductivos. En-

27 Vid. PUIGPELAT MARTÍ, F. «Bioética y Derecho»..., Op. cit.

${ }_{28}$ PECES-BARBA, Gregorio. «La libertad del hombre y el genoma». Derechos y Libertades, núm. 2. Instituto Bartolomé de las Casas. Madrid, 1993; pág. 330.

(C) UNED. Revista de Derecho UNED, núm. 24, 2019 
tre ellos destaca especialmente y como manifestación del derecho a disponer del propio material genético y al acceso a las técnicas de reproducción asistida, el derecho a la autodeterminación genética y a la maternidad subrogada, ambos ejemplos de derechos inconclusos en los que se refleja a la perfección el dilema jurídico que subyace en la mayor parte de los supuestos bioéticos, tal y como aquí se ha apuntado.

\section{EL VACÍO LEGAL DE LAS PRÁCTICAS DE GESTACIÓN SUBROGADA EN ESPAÑA}

No cabe duda que la irrupción de los postulados bioéticos en el campo de las técnicas médicas ha coadyuvado a remover los paradigmas tradicionalmente aceptados por la institución de la familia. Pero la fijación de los nuevos parámetros éticos no habría sido posible sin la contribución de una sólida y generalizada base de madurez social. Baste recordar a título de ejemplo la polarización de posturas que precedió a la aprobación de la Ley 13/2005, de 1 de julio, por la que se modificó el Código Civil (CC) en materia de derecho a contraer matrimonio ${ }^{29}$, introduciendo un polémico segundo párrafo en el artículo 44 CC en el que se equiparaban los requisitos y efectos de los contrayentes del mismo o diferente sexo, diluida doce años más tarde en una tónica general que podría ser calificada sin temor a equívocos de normalizada.

Precisamente, en gran parte de los casos el convenio matrimonial representa la base sobre la que se acaba por ejercer el derecho a crear o fundar una familia, tal y como resulta garantizado por el ordenamiento jurídico internacional. Así se contienen en el artículo 16 de la Declaración Universal de los Derechos Humanos, en el artículo 8 del Convenio Europeo para la protección de los Derechos Humanos y las Libertades Fundamentales, y en el artículo 9 de la Carta de los Derechos Fundamentales de la Unión Europea. Por su parte, en el marco de los principios rectores de la política social y económica, el artículo 39 de la Constitución Española (CE) remite el mandato a los poderes públicos para que aseguren la protección social, económica y jurídica de la institución.

Ahora bien, que exista un reconocimiento internacional del derecho a constituir una familia, así como una protección pública de la misma, no quiere decir que haya igualmente un consenso general en torno a las formas o modelos jurídicos que la configuran. Como

${ }^{29}$ Vid. BOE de 2 de julio de 2005. 
tampoco lo hay en lo referido a los caracteres en los que se deben desenvolver las relaciones paterno-filiales o los derechos de los menores en el seno de la institución familiar. Tanto unos como otros son derechos con robustos componentes consuetudinarios a los que los postulados bioéticos han obligado a evolucionar, y a los que, sin embargo, se les requiere un elevado grado de aceptación social antes de proceder a modificar alguno de los elementos que los conforman.

En efecto, en la mayor parte de estos casos, el legislador aún se muestra indeciso a la hora de regular el tipo de modelo que debe garantizar no sólo las nuevas relaciones paterno-filiales impulsadas desde la Bioética en términos generales, sino particularmente los derechos que atañen tanto a las mujeres gestantes como a los menores de edad en estos casos. Y mientras tanto, a la espera de una normativa que les dote de seguridad jurídica, tanto la modificación de sus elementos como la construcción de los nuevos principios que los ordenan, acaban enfocándose a partir de la hermenéutica judicial al efecto, demostrando también con ello la preeminencia de la Biojurisprudencia sobre una Biolegislación, parsimoniosa cuando no tardía o anquilosada con las demandas sociales.

En cualquier caso, en el presente trabajo nos ocuparemos del derecho a procrear como una manifestación más del derecho a la autodeterminación genética, reconocido tanto por la mayor parte de la doctrina como de la jurisprudencia. Cabe reconocer por tanto un derecho a la autodeterminación de la gestante vinculado al principio de la autonomía de la voluntad, entendido como esfera externa de ese reducto íntimo o agere licere que faculta al paciente para decidir sobre su propio cuerpo y, por extensión, a gestar por cuenta ajena o por cuenta de otros. Un reducto íntimo de inmunidad frente a terceros admitido por las Sentencias del Tribunal Constitucional (SSTC) 19/1985, de 13 de febrero, 120/1990, de 27 de junio y 137/1990, de 19 de julio, que capacitaría para reconocer el derecho a la gestación voluntaria y libremente aceptada por la mujer para procrear en sustitución de otros ${ }^{30}$.

En la actualidad, las técnicas de reproducción humana asistida ofrecen a la mujer subrogada dos vías para ejercitar este derecho. La más tradicional es aquella en la que la propia gestante contribuye con su útero y con el material genético a la formación del embrión, pero resulta también frecuente que la concepción tenga lugar a partir de otros elementos aportados por la futura pareja progeni-

30 Vid. SSTC19/1985, de 13 de febrero, 120/1990, de 27 de junio y 137/1990, de 19 de julio.

(C) UNED. Revista de Derecho UNED, núm. 24, 2019 
tora. Y en este supuesto, como apunta el profesor Vela Sánchez, se multiplican las opciones, pues los comitentes pueden participar en la gestación tanto con el óvulo como con el esperma, con el óvulo fecundado a la espera de esperma, o incluso con óvulo y esperma de terceros implantando en el útero de la gestante subrogada, que de este modo no aportaría carga genética alguna al futuro embrión ${ }^{31}$.

Este abanico de posibilidades capacita a la gestación subrogada como una de las prácticas más demandadas en nuestros días para hacer efectivo el derecho a la maternidad. Sin embargo y frente a la normalización que en la práctica supone para la institución familiar la celebración de matrimonios de parejas homosexuales tras la polémica social que envolvió su tramitación y aprobación parlamentaria, la vía de hecho para el reconocimiento de los derechos que configuran la gestación subrogada sigue generando en la actualidad toda una serie de debates éticos y jurídicos en torno a la cosificación de la mujer, la mercantilización de los embriones y el superior interés del menor que, a nuestro juicio y pese a la dificultad que entrañan, están próximos a converger.

En cuanto al primero de ellos, el debate se centra en la posibilidad de disponer del propio cuerpo como resultado del principio de autonomía de la voluntad. En este caso, la capacidad de agencia, y por extensión el derecho a procrear, capacitaría para entender que la mujer podría decidir voluntariamente también sobre algunas partes de su propio cuerpo, incluido el útero, a favor de terceros. La cuestión a determinar en estos casos es si esta interpretación flexible de la propiedad corpórea auspicia, como apunta Redondo Salceda, una puesta a disposición efectiva o por el contrario la misma constituye un límite al ejercicio de esa propiedad ${ }^{32}$.

Las teorías que consideran que las prácticas de gestación subrogada reducen a la mujer a un peligroso estado de cosificación, tratan de limitar dicho ejercicio del derecho a la propiedad. Fundamentalmente, dichas posturas parten de sectores feministas y tienen que ver con la mercantilización de este tipo de prestaciones. Pero no siempre fue así. En 1976 el abogado Noel Kane y el doctor Warren Ringold crearon el Surrogate Family Service Institute, con una doble finalidad: dotar de amparo legal a la figura y prestar servicio a

31 VELA SÁNCHEZ, Antonio José. «Gestación por sustitución o maternidad subrogada: el deseo a recurrir a las madres de alquiler». Diario La Ley. Sección Doctrina, n. ${ }^{\circ}$ 7608. Wolters Kluwer. Madrid, 2011; págs. 1-2.

${ }^{32}$ REDONDO SALCEDA, Lara. "Libre disposición sobre el cuerpo: la posición de la mujer en el marco de la gestación subrogada». Eunomía. Revista en Cultura de la Legalidad, n. ${ }^{\circ} 12$. Madrid. Universidad Carlos III. Madrid, 2017; pág. 140. 
las parejas con dificultades reproductivas que, a través de mujeres voluntarias, decidieran ejercer este derecho. Esto posibilitó que dos años más tarde naciera el primer bebé fruto de las técnicas de fecundación, y si bien el hecho fue acogido en un primer momento con entusiasmo desde posiciones feministas, encontrando aquí un hito en la ampliación del derecho a la autodeterminación procreativa y, por extensión, de la libertad femenina, a partir de los años ochenta del pasado siglo, la perspectiva cambió radicalmente y algunas corrientes llegaron a acusar a las técnicas de reproducción humana asistida de instrumentalizar y estar al servicio de supuesto control patriarcal sobre el cuerpo de la mujer.

En la actualidad esta tesis continúa prevaleciendo, por lo que desde distintos ámbitos se rechaza la gestación subrogada arguyendo que contribuye a la cosificación del cuerpo de la mujer, desvirtuando los derechos que atañen a la autonomía personal y a la dignidad humana. Para cierto sector feminista, la regulación del uso de las tecnologías reproductivas, desde lo concerniente a la dispensa de contraceptivos, pasando por métodos de diagnosis prenatal y empleo de técnicas de fecundación in vitro, hasta alcanzar las prácticas de gestación subrogada, no es otra cosa sino un "claro signo del interés del Estado por ejercer un control, cada vez más invasivo, sobre las elecciones reproductivas de las mujeres y sobre el cuerpo femenino, con el fin de determinar el espacio de lo lícito y de lo prohibido en el ámbito de la parentalidad, de la familia y de la sexualidad $»^{33}$.

Sin embargo, entendemos que el derecho a la autodeterminación de la mujer no se ve afectado desde el momento en que la gestante decide libre y voluntariamente suscribir un contrato para sustituir el derecho de una pareja a tener descendencia. El derecho a la dignidad humana también quedaría salvaguardado si se acredita que no existe coacción o que la decisión no está sometida a una contraprestación económica, tal y como quedó reflejado en el Informe anual sobre Derechos Humanos y Política Comunitaria, aprobado por el Parlamento Europeo el 17 de diciembre de 2015, en el que por otro lado se denuncian los casos en los que la función reproductiva es utilizada con fines mercantilistas ${ }^{34}$.

${ }^{33}$ FANLO CORTÉS, Isabel. «Derechos reproductivos y libertad de las mujeres: observaciones sobre el debate feminista». Revista de Derecho Privado, n. ${ }^{\circ} 32$. Bogotá. Universidad Externado de Colombia. Bogotá, 2017; pág. 40.

${ }^{34} \mathrm{El}$ informe completo puede consultarse en la sede electrónica del Parlamento Europeo. Vid. Http://www.europarl.europa.eu/sides/getDoc.do?pubRef=-//EP// TEXT+TA+P8-TA-2015-0470+0+DOC+XML+V0//ES. [Consultada el 7 de noviembre de 2018]. 
En este mismo sentido, cabe recordar que la ya mencionada STC 212/1996, de 19 de diciembre, por la que se otorgaba validez a las técnicas de reproducción humana asistida, advertía así mismo sobre la reprochabilidad de una eventual patrimonialización del embrión humano $^{35}$. Obviamente, tanto las prácticas abusivas o de explotación mercantilista de la mujer como las de tráfico y comercialización de embriones y seres humanos, deben ser desterradas de este tipo de convenios o acuerdos. Esta es una postura innegociable que, por otro lado, no obsta ni dificulta las propuestas de modificación del vigente artículo 10 de la Ley 14/2006, de 26 de mayo, sobre Técnicas de Reproducción Humana Asistida (LTRHA) ${ }^{36}$, cuando establece que:

«1. Será nulo de pleno derecho el contrato por el que se convenga la gestación, con o sin precio, a cargo de una mujer que renuncia a la filiación materna a favor del contratante o de un tercero.

2. La filiación de los hijos nacidos por gestación de sustitución será determinada por el parto.

3. Queda a salvo la posible acción de reclamación de la paternidad respecto del padre biológico, conforme a las reglas generales».

El precepto establece la nulidad de cualquier pacto o convenio, tanto oneroso como gratuito, que tenga por objeto la gestación por sustitución, al considerar la capacidad de gestar fuera del comercio de los hombres en el sentido contemplado en el artículo $1271 \mathrm{CC}$, interpretando que el embrión es res extra commercium o cosa fuera del ámbito de disposición privado. La redacción, otorgada en el artículo 10.1 LTRHA hace más de veinte años como fruto de una concepción social hoy superada, sin duda es deudora también del artículo $1275 \mathrm{CC}$, en el que se dispone que los contratos que se opongan a las leyes o a la moral son ilícitos y no producirán efecto alguno, aunque lo cierto es que, bajo este prisma, el convenio de gestación subrogada tan sólo podría alcanzar un grado de licitud moral cuando la prestación se realice de manera altruista y sin contraprestación económica, puesto que el ordenamiento jurídico castiga con penas de hasta cinco años de prisión el carácter lucrativo del mismo, tal y como previene el artículo 221.1. CP para aquel que «mediando compensación económica, entregue a otra persona un hijo, descendiente o cualquier menor aunque no concurra relación de filiación o parentesco, eludiendo los procedimientos legales de la guarda, acogimiento o adopción, con la finalidad de establecer una relación análoga a la de filiación.»

35 Vid. STC 212/1996, de 19 de diciembre.

${ }^{36} \mathrm{Vid}$. BOE de 27 de mayo de 2006. 
La redacción vigente del citado artículo 10.2 LTRHA contiene una concepción de la filiación derivada directamente del derecho romano, en la que a través del principio mater semper certa est viene a establecer que el niño nacido de la mujer gestante por subrogación siempre será considerado hijo de ésta. Y si la filiación queda determinada entonces por el parto, la puesta a disposición de cualquier tipo de descendencia a cambio de contraprestación económica estaría tipificada como delito. De este modo y más allá de consideraciones morales en torno a la ilicitud de la figura, la única posibilidad legal de su ejercicio sería regulando su naturaleza altruista o, en todo caso, compensatoria respecto a los gastos derivados únicamente de la asistencia médica gestacional.

Precisamente para salvaguardar tanto los derechos de la mujer gestante por subrogación como los de los progenitores subrogantes, en fecha de 5 de septiembre de 2017, el Grupo Parlamentario Ciudadanos presentó ante la Mesa del Congreso de los Diputados una Proposición de Ley reguladora del Derecho a la Gestación por Subrogación ${ }^{37}$. El artículo 5 de la misma fijaba el carácter altruista de la prestación, realizada en condiciones de libertad, igualdad y dignidad, así como en base a los principios de buena fe y solidaridad entre las partes. Además, contenía un régimen de infracciones y sanciones, en el que en relación con este asunto el artículo 24.2.c) $8 .^{\mathrm{a}}$ calificaba como infracción muy grave el pago de cualquier cantidad, dineraria o en especie, a la mujer gestante que contraviniera la naturaleza no comercial del derecho a la gestación subrogada.

La propuesta trata también de resolver la incertidumbre jurídica en torno a la filiación de los hijos nacidos mediante gestación por subrogación. En primer lugar, el artículo 11.2 del texto presentado determinaba que, en ningún caso, podría llegar a establecerse vínculo de filiación entre la mujer gestante por subrogación y el niño o niños que pudieran nacer. A los efectos previstos en el artículo 45 de la Ley 20/2011, de 21 de julio, del Registro Civil ${ }^{38}$, el artículo 12.2 de dicha Proposición de Ley, establece que en el promotor del acto de inscripción debía aportar copia autenticada del contrato de gestación por subrogación facilitada por el Registro Nacional de Gestación de Subrogación, cuya creación pasaría a regularse reglamentariamente.

37 Vid. Boletín Oficial de las Cortes Generales. Congreso de los Diputados, de 8 de septiembre de 2017.

38 Vid. BOE de 22 de julio de 2011. 
Como cabe entender, la virtualidad jurídica de lo anterior pasa por la derogación expresa del vigente artículo 10 LTRHA que se contiene en la Disposición Derogatoria Única de la misma propuesta. Pero la seguridad jurídica de la que se pretende dotar en la práctica al derecho de gestación subrogada en España no acaba de resolver las cuestiones de orden público internacional, que en torno a la problemática de la filiación se suscitan particularmente cuando la prestación se realiza en otros países. En efecto, en la actualidad prevalece un criterio legalista que en virtud del artículo 117.1 CE resulta ciertamente inexcusable, pero que en última instancia resulta contrario a los principios del orden público internacional como los que, entre otros, se evidencian de la doctrina emanada del Tribunal Europeo de Derechos Humanos. Y esta postura formalmente taxativa y rigurosa impide reconocer efectos jurídicos a las situaciones de hecho que se generan con la práctica de la gestación subrogada.

El problema se evidenció en 2008. En aquella ocasión, dos varones de nacionalidad española que se habían casado tres años antes, solicitaron la inscripción de dos niños nacidos mediante gestación subrogada en el Registro Civil Consular de Los Ángeles. El encargado registral denegó la solicitud en un primer momento, pero la posterior Resolución de la Dirección General del Registro y del Notariado, de 18 de febrero de 2009 la revocó, ordenando proceder a la inscripción al entender que en estos casos el Derecho español no hacía distinciones entre hijos adoptados e hijos naturales, ni tampoco a la hora de admitir la filiación entre personas del mismo sexo, aunque por encima de todo la resolución consideraba que en estos casos debía prevalecer el interés superior del menor. El Ministerio Fiscal recurrió la resolución ante el juzgado de primera instancia de Valencia n. ${ }^{\circ} 15$, que en su Sentencia 193/2010, de 15 de septiembre, llegó a anularla por resultar incompatible con las normas que a su juicio regulan aspectos esenciales de las relaciones familiares y de la filiación, en relación con los valores constitucionales de dignidad de la persona, respeto a su integridad moral y protección de la infancia fundamentalmente. Por nuestra parte y sin llegar a cuestionar los fundamentos jurídicos de la sentencia, nos parece oportuno exponer una serie de consideraciones extemporáneas contenidas en la misma, como ejemplo del argumentario expuesto por una parte de la sociedad respecto a este asunto. Así, el juzgador de instancia considera que:

«Sin entrar a valorar el carácter fraudulento o no de la acción lo que es claro es que nos encontramos ante un matrimonio español que acuden a California, Estado Americano que junto con otros del mismo país y unos cuantos países más del mundo (Bélgica, Rusia, In- 
dia etc.) en los que es legal la gestación por sustitución, a diferencia de en España, la única justificación posible a su acción es clara son conocedores que en España la gestación por sustitución está prohibida y que de producirse el alumbramiento en este país no podrían inscribir a los nacidos como hijos naturales de ambos.

Es por ello y no por otra razón por la que acuden a California con el conocimiento de que allí está permitido y que allí los bebes podrán ser inscritos en su registro civil como hijos naturales de ambos, pero también son conocedores que los registros españoles ponen trabas a la inscripción tal como ellos la pretenden, ello no obstante asumen el riesgo y actúan con conocimiento de que en cualquiera de las sucesivas instancias hasta la presente e incluso venideras su voluntad de proceder a inscribir a los nacidos como hijos naturales de ambos podía ser desestimada, pasando de una cuestión de probabilidad a absoluta certeza caso de que el nacimiento se hubiese producido en España, es por ello por lo que deciden acudir a EEUU, asumiendo con ello la consecuencia que su decisión conlleva» ${ }^{39}$.

A la vista de lo anterior, la Dirección General de los Registros y del Notariado, dictó una Instrucción, de 5 de octubre de $2010^{40}$, sobre el régimen registral de filiación de los nacidos mediante gestación por sustitución, aceptando la inscripción de nacimiento en el extranjero si, junto a la solicitud de inscripción, se presentaba una resolución judicial dictada por un tribunal competente determinando la filiación del nacido. Con esta solución se trataba de proteger el interés superior del menor, pero también de las mujeres que se prestan a la subrogación renunciando a sus derechos como madres. Sin embargo, la posición jurisprudencial difería por el momento de reconocer dichas garantías. La Sentencia de la Audiencia Provincial (SAP) de Valencia 826/2011, de 23 de noviembre, confirmó el pronunciamiento de instancia y, finalmente la Sentencia del Tribunal Supremo (STS) 835/2014, de 6 de febrero, cerró las puertas a la posibilidad de inscripción de los niños nacidos por gestación subrogada. Precisamente, en este último pronunciamiento también hacía alusión a la «huida» consciente y premeditada de los solicitantes de la inscripción del Derecho español, y en especial del artículo 10 LTRHA mediante la que se procedería a declarar radicalmente nulo el contrato de gestación por sustitución, así como la filiación de los padres intencionales o comitentes respecto de los niños nacidos del mismo, argumentado que:

«En nuestro ordenamiento jurídico y en el de la mayoría de los países con ordenamientos basados en similares principios y valores,

${ }^{39}$ Vid. Sentencia del juzgado de primera instancia de Valencia n. ${ }^{\circ} 15,193 / 2010$, de 15 de septiembre.

${ }^{40}$ Vid. BOE de 7 de octubre de 2010. 
no se acepta que la generalización de la adopción, incluso internacional, y los avances en las técnicas de reproducción humana asistida vulneren la dignidad de la mujer gestante y del niño, mercantilizando la gestación y la filiación, "cosificando» a la mujer gestante y al niño, permitiendo a determinados intermediarios realizar negocio con ellos, posibilitando la explotación del estado de necesidad en que se encuentran mujeres jóvenes en situación de pobreza y creando una especie de "ciudadanía censitaria» en la que solo quienes disponen de elevados recursos económicos pueden establecer relaciones paterno-filiales vedadas a la mayoría de la población $»^{41}$.

Como cabe comprobar, el Tribunal Supremo hizo prevalecer aquí un enfoque generalizador, centrado en los riesgos inherentes de mercantilización del menor y el atentado a la dignidad de la mujer gestante que eventualmente sufriría un estado de necesidad, y evitó entrar al fondo de la casuística que se le exigía. En este caso, resultaba incontrovertible que apoyar la negativa a la inscripción de filiación en otros bienes jurídicamente protegidos que no fueran el prevalente interés del menor, llevaba aparejada la inevitable desprotección de éste en el ámbito de las relaciones paterno-filiales. Quizás, como apunta el catedrático Gerardo Ruiz-Rico, la resolución debiera haberse desenvuelto no tanto en enjuiciar la validez del contrato en términos de legalidad interna, sino bajo parámetros de orden técnico-jurídico que pasasen por el reconocimiento de una decisión extranjera válida y legal conforme a su normativa ${ }^{42}$.

Precisamente, esta fue la óptica adoptada al poco tiempo en dos Sentencias del Tribunal Europeo de Derechos Humanos, en las que se acabó por condenar a Francia e Italia por su negativa a reconocer la filiación de unos niños nacidos en Estados Unidos a través de técnicas de gestación subrogada, al entender que se producía una clara vulneración del derecho a la intimidad personal y familiar consagrado en el artículo 8 del Convenio Europeo de los Derechos Humanos. En la Sentencia del Tribunal Europeo de Derechos Humanos (STEDH), Caso Mennesson y Labassee contra Francia, de 26 de junio de 2014, se reconoció un vínculo indisoluble entre el derecho a la vida privada y a la propia identidad, con la gestación por subrogación y con el reconocimiento de la filiación derivada de la misma ${ }^{43}$.

${ }^{41}$ Vid. STS 835/2014, de 6 de febrero.

${ }^{42}$ RUIZ-RICO RUIZ, Gerardo. «La problemática constitucional derivada de las técnicas de reproducción humana asistida (TRHA): el caso de la maternidad subrogada)». Revista de Derecho Político, n. ${ }^{\circ}$ 99. Universidad Nacional de Educación a Distancia. Madrid, 2017; pág. 65.

${ }^{43}$ Vid. STEDH, Caso Mennesson y Labassee contra Francia, de 26 de junio de 2014 
La conexión entre estos derechos vendría reforzada por la superior protección del interés del menor, que en otro caso quedaría seriamente afectado por la incertidumbre jurídica que supone la negación de la inscripción registral. No obstante y si bien la STEDH, Caso Paradiso y Campanelli contra Italia, de 27 enero 2015, se reafirmó en idénticos fundamentos, hay que decir que la posterior STEDH, Gran Sala, Caso Paradiso y Campanelli contra Italia, de 24 de enero de 2017, admitió que las autoridades italianas podían retirar la custodia a los padres no biológicos, tras acreditarse que el contrato de subrogación se realizó de manera ilegal ${ }^{44}$.

Las conclusiones contenidas en la STEDH, Caso Mennesson y Labassee contra Francia, de 26 de junio de 2014, hicieron plantear un incidente de nulidad basado en el interés prevalente de los menores, pero el Auto del Tribunal Supremo de 2 de febrero de 2015, resolvió que este caso:

«No existe una situación de incertidumbre equiparable a la de los menores de los casos resueltos por el Tribunal de Estrasburgo, que se veían imposibilitados de por vida para ver reconocida su filiación por el ordenamiento jurídico nacional, con las consecuencias que ello traía respecto de la adquisición de la nacionalidad francesa y sus derechos sucesorios. En nuestro caso, los inconvenientes que puedan surgir en el proceso de fijación de la filiación biológica paterna y de adopción son transitorios, superables, y no alcanzan un nivel de gravedad tal que puedan considerarse constitutivos de un desequilibrio entre los intereses de la comunidad, fijados en su legislación sobre filiación y reproducción humana asistida, y el interés de los menores. Además, como se ha dicho, en ese periodo transitorio regirá el criterio de protección de la unidad familiar «de facto» que al parecer existe, para el caso de que surjan problemas en relación a la situación de los menores» ${ }^{45}$.

En cualquier caso, la doctrina emanada del Tribunal de Estrasburgo ratificó a la Dirección General del Registro y del Notariado en su primera decisión y, mediante una Circular emitida el 11 de julio de 2014, resolvió mantener la vigencia de la Instrucción de 5 de octubre de 2010, sobre régimen registral de filiación de los nacidos mediante gestación por sustitución. Hay que decir que esta interpretación estuvo a punto de prevalecer en el Proyecto de Ley de Medidas de Reforma Administrativa en el ámbito de la Administración de Justicia y del Registro Civil, presentado por el Gobierno el 18 de junio de 2014. En efecto, el artículo segundo del proyecto pretendía la

${ }^{44}$ Vid. SSTEDH, Caso Paradiso y Campanelli contra Italia, de 27 enero 2015, y posterior de Gran Sala, de 24 de enero de 2017.

${ }^{45}$ Vid. ATS de 2 de febrero de 2015 
modificación del artículo 44.7 de la Ley 20/2011, de 21 de julio, del Registro Civil ${ }^{46}$, con la siguiente redacción:

«En los casos de nacimiento fuera de España, cuyo régimen de filiación esté sujeto a la legislación extranjera, se consignará en todo caso la filiación materna correspondiente a la madre que ha gestado, siendo necesaria para hacer constar la filiación no matrimonial la declaración conforme de ambos sobre dicha filiación; si la madre estuviera casada y la legislación extranjera lo exigiera, se precisará la conformidad del o la cónyuge respecto de tal filiación. En cualquier otro caso, para la inscripción en el Registro Civil de la filiación del nacido será necesario que haya sido declarada en una resolución judicial reconocida en España mediante un procedimiento de exequátur».

Finalmente, el desacuerdo entre los distintos grupos políticos en torno a cuestiones de técnica jurídica impidieron la aprobación del último inciso, pero la interpretación de la Dirección General del Registro y del Notariado en relación al reconocimiento de la filiación continúa prevaleciendo entre los tribunales españoles, que no dudan en desestimar este tipo de pretensiones cuando la solicitud de inscripción no viene avalada por un órgano jurisdiccional del país de origen. A título de ejemplo, este es el caso de la Sentencia del Tribunal Superior de Justicia (STSJ) de la Comunidad de Madrid 209/2017, de 13 marzo, donde se desestimó la pretensión de su reconocimiento al no acreditarse que hubiera sido dictada resolución alguna por los órganos judiciales rusos, que determinase en este caso la filiación española del menor respecto de los progenitores subrogantes ${ }^{47}$.

Obviamente, estos pronunciamientos afectan a bienes constitucionalmente protegidos, como la dignidad de la mujer y el interés prevalente del menor, denigrados de manera flagrante en tanto la legislación española no resulte adaptada a los postulados que garantizan dichos derechos desde el orden internacional. La reforma legislativa implicaría, además y siguiendo al catedrático Ruiz-Rico en este punto,

«Otorgar una relevancia que hoy parece no tener la voluntad o «derecho a procrear», como una dimensión de la autonomía de la voluntad enclavada en el contenido esencial del artículo 18 de la CE (intimidad personal), a la luz de la doctrina jurisprudencial supranacional que se ha consolidado ya del artículo 8 del $\mathrm{CEDH} »^{48}$.

$46 \mathrm{Vid}$. BOE de 22 de julio de 2011.

47 Vid. STSJ de la Comunidad de Madrid 209/2017, de 13 marzo.

${ }^{48}$ RUIZ-RICO RUIZ, G. Op.cit; pág. 73. 
Con todo, esta parece ser la línea jurisprudencial que se ha abierto a partir de las SSTS de 25 de octubre y 16 de noviembre de 2016, donde en aplicación del principio de analogía se ha reconocido por primera vez el derecho a la prestación de maternidad respecto a sendos casos de gestación subrogada ${ }^{49}$. En efecto, hasta este momento existía un importante acervo de resoluciones judiciales dictadas por las Salas de lo Social de los diferentes Tribunales Superiores de Justicia, pronunciándose en sentido dispar acerca del reconocimiento o no de la prestación. A título de ejemplo, baste señalar que a favor de la misma se habían pronunciado las Sentencias del Tribunal Superior de Justicia (SSTSJ) de Madrid, de 8 de octubre de 2012, 3 de marzo de 2013, 23 de diciembre de 2014, 17 de julio de 2015, 12 de febrero de 2016 y 31 de marzo de 2016; así como las SSTSJ de Cataluña de 23 de noviembre de 2012, 9 de marzo de 2015, 1 de julio de 2015, 15 de septiembre de 2015 y 11 de febrero de 2016. Mientras que en sentido opuesto, se habían dictado las SSTSJ de Madrid, de 7 de julio de 2014 y 5 de octubre de 2015; junto a las SSTSJ del País Vasco, de 13 de mayo de 2014 y 3 de mayo de 2016.

Por su parte, el 18 de marzo de 2014, el Tribunal de Justicia de la Unión Europea había dictado dos sentencias, en relación con sendas cuestiones prejudiciales, asuntos C-167/12 y C-363/2012, instadas desde Reino Unido e Irlanda, denegando el derecho a la prestación de maternidad solicitada ${ }^{50}$. En ambos casos, el Tribunal de Justicia de la Unión Europea llegó a interpretar que, ni el artículo 8 de la Directiva 92/85 /CEE del Consejo, de 19 de octubre de 1992, relativa a la aplicación de medidas para promover la mejora de la seguridad y de la salud en el trabajo de la trabajadora embarazada, que haya dado a luz o en período de lactancia, ni el artículo 14 de la Directiva 2006/54/CE del Parlamento Europeo y del Consejo, de 5 de julio de 2006, relativa a la aplicación del principio de igualdad de oportunidades e igualdad de trato entre hombres y mujeres en asuntos de empleo y ocupación, reconocían este derecho respecto de las madres subrogantes.

Por el contrario, el Tribunal Supremo entendió que las directivas comunitarias garantizaban un nivel protector básico y que correspondía a los ordenamientos estatales incrementar discrecionalmente dicho estándar de protección, razonando entonces que en estos supuestos debía prevalecer el interés del menor que, en otro caso, quedaba peligrosamente desprotegido. La STS de 25 de octubre de 2016, estimó aplicable por analogía lo previsto a estos efectos en el

49 Vid. SSTS de 25 de octubre y 16 de noviembre de 2016.

50 Vid. SSTJUE de 18 de marzo de 2014, asuntos C-167/12 y C-363/2012. 
artículo 3.2 del Real Decreto 295/2009, de 6 de marzo, por el que se regulan las prestaciones económicas del sistema de la Seguridad Social por maternidad, paternidad, riesgo durante el embarazo y riesgo durante la lactancia natural ${ }^{51}$, en el cual, ante el fallecimiento de la madre biológica y la supervivencia del menor, se opta por transferir al padre la prestación económica por maternidad.

En este sentido, hay que recordar que el artículo $39.3 \mathrm{CE}$ obliga a los padres a prestar asistencia a los hijos habidos dentro o fuera del matrimonio, por lo que la STS de 25 de octubre de 2016, llegaba a razonar que:

«Una Ley Civil prescriba la nulidad del contrato de maternidad por subrogación no elimina la situación de necesidad surgida por el nacimiento del menor y su inserción en determinado núcleo familiar; y tal situación de necesidad debe ser afrontada desde la perspectiva de las prestaciones de Seguridad Social procurando que esos hijos no vean mermados sus derechos $»^{52}$.

Y en similares términos se pronunció la STS de 16 de noviembre de 2016, casando y anulando la sentencia de instancia en la que no se reconocía el derecho a la prestación por maternidad de una gestante por subrogación, en atención al carácter prevalente del interés del menor. El Tribunal Supremo entendió que, de no otorgarse esta protección, se produciría una discriminación en el trato contraria a los artículos 14 y $39.2 \mathrm{CE}$, puesto que acreditado el núcleo familiar:

«Si los menores tienen relaciones familiares de facto con los recurrentes, la solución que haya de buscarse tanto por los recurrentes como por las autoridades públicas que intervengan, habría de partir de este dato y permitir el desarrollo y la protección de estos vínculos. En el asunto examinado el menor, nacido tras la gestación por sustitución, forma un núcleo familiar con los padres comitentes, que le prestan atención y cuidados parentales y tienen relaciones familiares de facto, por lo que debe protegerse este vínculo, siendo un medio idóneo la concesión de la prestación por maternidad $»^{53}$.

A la vista de lo anterior podría decirse a modo de conclusión que las SSTS de 25 de octubre y de 26 de noviembre de 2016, han sentado jurisprudencia adelantado las futuras líneas interpretativas que, en torno a los derechos relacionados con las técnicas de reproducción humana asistida y la gestación subrogada, conformarán los pronunciamientos de los tribunales ordinarios. En nuestra

51 Vid. BOE de 21 de marzo de 2009.

52 STS de 25 de octubre de 2016

53 STS de 16 de noviembre de 2016. 
opinión, por encima del debate bioético, este es el papel que está llamada a ejercer la Biojurisprudencia como antesala de la Biolegislación. Ambas disciplinas deben anteponer la seguridad jurídica para garantizar la protección de la mayor parte de los intereses en juego, a pesar de la dificultad que entraña en el ámbito de la Bioética gestionar la ecuación en la que se desenvuelven los derechos de nueva generación. La efectividad de su resolución es uno de los retos más importantes a los que se enfrenta el Bioderecho en nuestros días.

\section{BIBLIOGRAFÍA}

Aparisi Miralles, Ángela. «Bioética, Bioderecho y Biojurídica (Reflexiones desde la filosofía del derecho)». Anuario de Filosofía del Derecho, n. ${ }^{\circ}$ 24. Sociedad Española de Filosofía Jurídica y Política. Madrid, 2007.

Beauchamp, Tom L., Childress, James Franklin. Principles of Biomedical Ethics. Oxford University Press. Nueva York, 1979.

FANLO CORTÉs, Isabel. «Derechos reproductivos y libertad de las mujeres: observaciones sobre el debate feminista». Revista de Derecho Privado, n. ${ }^{\circ}$ 32. Bogotá. Universidad Externado de Colombia. Bogotá, 2017.

Gracia Guillén, Diego. Procedimientos de decisión en ética clínica. Eudema. Madrid, 1991.

JAHR, Fritz. «Bioethics. A panorama of the human being's ethical relations with animals and plants». Kosmos, Gesellschaft der Naturfreunde. Stuttgart, 1927.

Marabel Matos, Jacinto J. El Derecho Fundamental de Libertad Religiosa en el ámbito de los servicios públicos sanitarios. Dykinson. Madrid, 2017.

Martín Sanchez, Isidoro (Coord.). Bioética, Religión y Salud. Consejería de Sanidad y Consumo de la Comunidad de Madrid. Madrid, 2005; pp. 17-20.

Peces-Barba, Gregorio. «La libertad del hombre y el genoma». Derechos y Libertades, núm. 2. Instituto Bartolomé de las Casas. Madrid, 1993.

PotTer, Van Rensselaer. «Bioethics, the Science of Survival». Perspectives in Biology and Medicine. Vol. XIV, $\mathrm{n} .{ }^{\circ}$ 1. University of Kansas Medical Center. 1970. 
Potter, Van Rensselaer Bioethics: Bridge to the future. Englewood Cliffs. New Jersey. 1971.

Puigpelat Martí, Francesca. «Bioética y Derecho», en Atienza RodríGuEz, M. (coord.) Teoría del Derecho y Filosofía del Derecho. Base de datos de bibliografía jurídica. Iustel. Madrid, 2003.

Rawls, John. A Theory of Justice. Oxford University Press. Nueva York, 1999.

REDONDo SALCEDA, Lara. "Libre disposición sobre el cuerpo: la posición de la mujer en el marco de la gestación subrogada». Eunomía. Revista en Cultura de la Legalidad, n. ${ }^{\circ} 12$. Madrid. Universidad Carlos III. Madrid, 2017.

ReIcH, Warren T. Encyclopedia of Bioethics. Vol. I. MacMillan Free Press. Nueva York. 1978.

RUIz-RIco RuIz, Gerardo. «La problemática constitucional derivada de las técnicas de reproducción humana asistida (TRHA): el caso de la maternidad subrogada)». Revista de Derecho Político, n. ${ }^{\circ} 99$. Universidad Nacional de Educación a Distancia. Madrid, 2017.

VELA SÁNChEZ, Antonio José. «Gestación por sustitución o maternidad subrogada: el deseo a recurrir a las madres de alquiler». Diario La Ley. Sección Doctrina, n. ${ }^{\circ}$ 7608. Wolters Kluwer. Madrid, 2011. 